\title{
In Appreciation of Helene Pavlov, MD, FACR, Radiologist-in-Chief, 1997-2013
}

\section{Editorial}

\author{
Carolyn M. Sofka, MD
}

Received: 14 July 2014/Accepted: 18 July 2014/Published online: 26 August 2014

(C) Hospital for Special Surgery 2014

In this special issue of the HSS Journal, we take the time to thank and reflect on the service of Dr. Helene Pavlov, who served as the Radiologist-in-Chief of the Department of Radiology and Imaging for 16 years from April 1, 1997 through November 30, 2013.

Dr. Pavlov was one of the first musculoskeletal imaging Fellows at Hospital for Special Surgery (1976-1977). Dr. Pavlov's contributions to the field of musculoskeletal radiology are extensive: Dr. Pavlov was one of the first to write on the conventional arthrographic findings of anterior cruciate ligament tears. She also described radiographic findings in various sports injuries including often difficult to diagnose entities such as navicular stress fractures. She further reported on patterns of athletic cervical spine injuries and their predisposing factors. In 1994, The Association of Bone \& Joint Surgeons awarded Dr. Pavlov the Nicholas Andry Award For Outstanding Achievement in the Field of Orthopaedic Surgery for her work on "The Relationship of Mechanical Deformation of the Cervical Cord to Reversible, Incompletely Reversible and Irreversible Neural Injury." Further, in 1997, Dr. Pavlov received the North American Spine Society Award for Outstanding Research Paper in Orthopaedics for "Pathomechanics and Pathophysiology of Cervical Spinal Cord Injury" which was augmented in 2004 by the Orthopaedic Research Society/AAOS Elizabeth Winston Lanier Kappa Delta Award.

Electronic supplementary material The online version of this article (doi:10.1007/s11420-014-9411-y) contains supplementary material, which is available to authorized users.

C. M. Sofka, MD $(\bowtie)$

Department of Radiology and Imaging,

Hospital for Special Surgery,

535 East 70th Street,

New York, NY 10021, USA

e-mail: sofkac@hss.edu

C. M. Sofka, MD

Weill Cornell Medical College,

New York, NY 10035, USA
Dr. Pavlov has not only significantly enriched the musculoskeletal imaging literature, but she has also contributed an extensive amount of time to the promotion of Radiology as well. She has championed the appropriate use of imaging and radiation hygiene. She has been a member of the International Skeletal Society since 1980, serving as the past president of the New York Roentgen society from 20092010 and serving on many appropriateness criteria panels for the American College of Radiology.

In this special issue, current colleagues and former Fellows have contributed works to reflect the current status of musculoskeletal radiology, many of them stemming from the seeds planted during their education and training as musculoskeletal radiology Fellows at Hospital for Special Surgery under Dr. Pavlov's tenure.

Dr. Lynne Steinbach (Fellow, Hospital for Special Surgery 1983-1984), who is currently at University of California, San Francisco, contributed with her coauthors "Lesser tuberosity avulsions in adolescents," an often overlooked injury; however, one that can be identified if one meticulously reviews the radiographs as Dr. Pavlov has certainly instructed us all to do throughout the years.

Other former Fellows include Dr. Scot Campbell and Dr. Jean Jose, who have contributed manuscripts on "Posterior chondrolabral cleft: clinical significance and associations with shoulder instability" and "Ultrasound-guided percutaneous long head of the biceps tenotomy: a novel technique with case report," respectively, demonstrating the importance and added diagnostic abilities of advanced cross sectional imaging modalities such as MRI and ultrasound, that have become integral to our world of musculoskeletal imaging. Of note, one of the coauthors on Dr. Jose's paper is one of our newest Fellows (class of 2015) demonstrating the positive reputation and tradition of the Radiology Fellowship program at Hospital for Special Surgery that Dr. Pavlov helped to develop.

Lastly, former Fellows who are now attending radiologists at Hospital for Special Surgery have also contributed to this special issue including Dr. Douglas Mintz, Dr. Kenny Nwawka, Dr. Darryl Sneag and our current Chairman, Dr. Hollis G. 
Potter. Dr. Doug Mintz has teamed up with yet another former Fellow, Dr. Sinchun Hwang, who is currently an attending radiologist at Memorial Sloan Kettering Cancer Center, to write on the importance of imaging in the evaluation of bone tumors ("Bone tumor imaging: then and now") while Dr. Potter's team describe the current state of the art of magnetic resonance imaging techniques with appropriate metal artifact reduction sequences in the setting of arthroplasty ("Magnetic resonance imaging of shoulder arthroplasty").

In closing, Dr. Jean Jose (Fellow, 2007-2008) notes the following:

Medical imaging has undergone more dramatic changes and reinventions during Dr. Pavlov's tenure than any other specialty. Amidst the current transition period in healthcare, it is wise to examine and learn from great physicians who contributed and thrived during similar challenging times. Thank you, Helene, for doing what great teachers have always done: leading by example, education by inspiring, and motivating by appreciating
At this time, we look back and thank Dr. Pavlov for her years of service to the Department of Radiology and Imaging. Yet, at the same time, we eagerly anticipate the next chapter of the Department. Under the leadership of Dr. Potter, we plan to continue to build and expand on the many contributions of Dr. Pavlov.

Carolyn M. Sofka

MD FACR New York, New York

\section{Disclosures}

Conflict of Interest: Carolyn M. Sofka, MD has declared that she has no conflict of interest.

Human/Animal Rights: This article does not contain any studies with human or animal subjects performed by the any of the authors.

Informed Consent: N/A

Required Author Forms Disclosure forms provided by the authors are available with the online version of this article. 